\title{
A comprehensive model for process selection by considering offline and online quality control
}

\author{
Mohammad Adam JERUSALEM *, Shi-Woei LIN * and Dradjad IRIANTO ** \\ * Department of Industrial Management, National Taiwan University of Science and Technology \\ No.43, Sec. 4, Keelung Rd., Da'an Dist., Taipei 106, Taiwan \\ E-mail: mohadamjerusalem@gmail.com \\ ** Department of Industrial Engineering, Bandung Institute of Technology \\ No. 10, Ganesha, Bandung 40132, Indonesia
}

\section{Received 9 March 2016}

\begin{abstract}
Offline and online quality control are vital aspects to maintain quality since they help to reduce the deviation of the target product and to avoid any out-of-control manufacturing conditions. In contrast to extant studies which only highlighted the importance of online quality control, this study proposes a new comprehensive model for process selection. It incorporates both offline and online quality controls, an excellent balance between the costs, tolerance as a quality requirement, and delivery time. In particular, the proposed model tries to optimize the total cost, which comprises the design, prevention, manufacturing, inspection-correction, and finishing costs as well as the loss of quality, by considering the tolerance and delivery schedule. This model then selects the process with the cheapest total cost, a tolerance level that is more lenient than the tightest tolerance, and a reasonable delivery time. A distinguishing feature of the presented model compared to other studies about process selection is that the costs are related to the product design, which makes this model compatible with more than one product design. The model is also robust to changes in some of the parameters. Therefore, it can be implemented in numerous situations.
\end{abstract}

Key words : Cost, Delivery, Offline quality control, Online quality control, Quality

\section{Introduction}

One competitive priority in operations that is critical to a firm is the augmentation of a position in the market. For a manufacturing firm, emphasizing its competitive priority may lead to decisions regarding their production process, planning, capacity and control (Boyer and Lewis, 2002). This priority may also relate to their manufacturing capabilities, including the cost, quality, flexibility, and delivery time (Boyer and Lewis, 2002; Fine et al., 2005; Andolfatto et al., 2014) amongst other dimensions to their service and environment (Díaz-Garrido et al., 2011).

To maintain quality, a manufacturer conducts offline quality control tests in the product design phase to reduce the deviation of the target product, whereas online quality control is conducted during the production process phase in which issues are anticipated and corrected to avoid any out-of-control manufacturing conditions. Offline quality control is mainly a preventive measure used in the stages of product development or manufacturing system design to make sure the product can be designed or made less sensitive to the effects of random variation in manufacturing, environment, or even customer usages. On the other hand, online quality control emphasizes on monitoring and surveillance of the production process to identify the anomaly and to analyze and remove the causes of variation (Aravindan et al., 1995; Onwubolu, 1997).

Tolerance synthesis is a critical issue in the design and production stages, and affects both the product and process design because the tolerance is the link between the product requirements and manufacturing cost (Zhang, 1997). Tolerance synthesis reflects a tradeoff between customer requirements and the ability of producers to satisfy them. Hence, the loss of both the customers and producers can be equalized (Gryna et al., 2005). The tolerance can be broken into two classes; 1 ) design tolerances, in which the tolerance allocation is performed in the product design phase, and 2) 
manufacturing tolerances, which focus on tolerance relaxation during the production process. Tolerance synthesis must be considered in both the product and process designs. It represents an interactive process between the design and manufacturing decision making (Singh et al., 2009; $\mathrm{Li}$ et al., 2009). Because the tolerance relates to the costs, the allocation of optimal tolerance values should take both quality loss and manufacturing costs into account when considering the design and tolerance constraints (Feng et al., 2001; Mustajib 2012; Muda and Hendry, 2002; Lin 2012).

Make-to-order (MTO) manufacturing has several crucial aspects in the production planning process. For example, Muda and Hendry (2002) mentioned that the issue of process flexibility needed in the MTO sector may lead to strategic decisions to preserve a functional layout rather than alter the cellular configuration of the plant. Many studies have been conducted to analyze the manufacturing systems in MTO environments. Haskose et al. (2004) studied the performance analysis of MTO manufacturing systems, and crafted a queuing network model with a limited capacity for every workstation. Calosso et al. (2003) created a three-tier, mixed-integer, linear programming model to standardize the negotiation process in a multi-enterprise. Ebadian et al. (2008) proposed a structure of decision-making for the order entry stage in MTO manufacturing based on the price and delivery time.

Turning to studies regarding tolerance allocation, Wang and Liang (2005) suggested that machining parameter, process selection and tolerance synthesis were the three key issues in reducing production cost and ensuring product quality. They addressed the three issues simultaneously by considering both tangible and intangible costs. Robles and Roy (2004) developed an optimization model for tolerance and process sequence selection. They integrated the quality loss as the consequence of failing to meet target dimensions and the manufacturing tolerance cost. Peng et al. (2008) proposed a method to balance manufacturing cost and quality loss by allocating the required functional assembly tolerances to the design and process tolerances.

Determination of the most proper machining methods for a part to be manufactured is one of the key activities in process planning. Tehrani et al. (2007) developed a search algorithm for creating and seeking the process plan networks, while Shimizu et al. (2011) optimized sequencing planning of mixed-model assembly line for reducing the work-in-process inventory between the processes. Dwijayanti and Aoyama (2014) proposed a system in the complex machining environment by developing an automatic process planning based on the machining feature recognition. Irianto and Rachmat (2008) formulated a model to optimize process selection that accounts for appraisal costs. In order to improve quality in multi-stage processes and to maximize profit, Mustajib and Irianto (2010) developed a model of processes alternative selection and production unit determination for each stage. These last two studies constructed models related to the quality, but only considered online quality control. Irianto and Rachmat (2008) only measured inspection-correction and finishing costs in the appraisal cost, while Mustajib and Irianto (2010) only considered the manufacturing, quality loss, rework, and scrap, and quality improvement implementation costs in the total cost. Furthermore, both models were restricted to one product design.

Although research discussed above tried to formulate a unified model for achieving better tolerance design or process selection for MTO manufacturing, these studies have emphasized mainly on elements related to the online quality control. Comparatively little attention has been paid to incorporate components of the offline quality control into the model. The objective of this study is to offer a new comprehensive model for process selection that accounts for both online and offline quality control while balancing the cost, delivery time, and quality. A comprehensive model of the process selection is essential to enrich our understanding of manufacturing systems, including MTO manufacturing. To this end, we crafted an approach for process selection that provides contributions such as:

(a) gives a thorough consideration of the product design and production process phase,

(b) provides a compromise between the cost, quality, and delivery as three important dimensions to the competitive priority in operations,

(c) is appropriate for more than one product design,

(d) and offers consideration of the sharing losses of both the manufacturer and customer.

\section{The Problem}

Some of the key characteristics of MTO companies include their limited number of standard products, multi-task machinery, adaptable workers, and product demands that are both unstable and unpredictable. These characteristics make product lead times even more vital for customer satisfaction. MTO companies need to control potential issues in the product design and production process phases (e.g., process flexibility, process selection, product quality, and delivery time) as a consequence of their characteristics; otherwise, they will have increased costs, a lack of quality, and longer delivery times. 
With regards to tolerance synthesis and quality control, separating the models for the offline and online quality control leads to sub-optimal solutions because each model could make sequential, locally optimal choices. Therefore, a comprehensive model for decision making in the product design and production processes will significantly affect the performance of MTO manufacturing.

\section{The Proposed Model}

This new comprehensive model for the process selection decision making explicitly formulate the offline and online quality control costs that relate the design and manufacturing processes. In particular, the design and prevention costs are associated with efforts in conducting offline quality control for the prevention of nonconformance, whereas the appraisal costs (e.g., loss of quality, inspection-correction cost, and finishing cost) are costs associated with online quality control when a company try measuring and evaluating its products. Additionally, this model also considers manufacturing cost and constraints specific to the order (i.e., tolerance synthesis, processing time, and number of units produced). The nomenclature used for this model follows:

\section{Indices:}

$h \quad:$ product design $h$,

$i \quad$ : process phase $i$,

$j \quad$ : manufacturing process alternative $j$,

Nh : number of alternatives of the product design,

$\mathrm{Nr} \quad$ : number of the process phase,

Mi : number of alternative of the manufacturing process for process phase $i$,

$p \quad$ : prevention process $p$,

$f \quad$ : finishing process $f$.

Parameters:

$c d_{h} \quad$ : design cost for product design $h$,

$c p_{h} \quad:$ prevention cost for product design $h$,

$\mathrm{cm}_{h i j} \quad$ : manufacturing cost for manufacturing process alternative $j$, process phase $i$, product design $h$,

$c i_{h i j} \quad$ : inspection-correction cost for manufacturing process alternative $j$, process phase $i$, product design $h$,

$c f_{h j} \quad$ : finishing cost for manufacturing process alternative $j$, product design $h$,

$\left.\frac{\partial y}{\partial x}\right|_{\tau_{x h i}}:$ partial derivative of the functional dimension with respect to process phase $i$ and product design $h$,

$\bar{P}_{h i j}$ : probability of not conforming to the specifications for manufacturing process alternative $j$, process phase $i$, and product design $h$,

$t_{h i j} \quad$ : tolerance for manufacturing process alternative $j$, process phase $i$, product design $h$,

$t_{k} \quad$ : tolerance design,

$A_{p} \quad$ : estimated quality loss coefficient,

$n d_{h} \quad$ : number of product with design $h$ produced,

$n p_{h i j} \quad$ : number of unit in prevention process for manufacturing process alternative $j$, process phase $i$, product design $h$,

$n i_{h i j} \quad$ : number of unit in inspection process for manufacturing process alternative $j$, process phase $i$, product design $h$,

$n f_{h j} \quad$ : number of unit in finishing process for manufacturing process alternative $j$, product design $h$, 


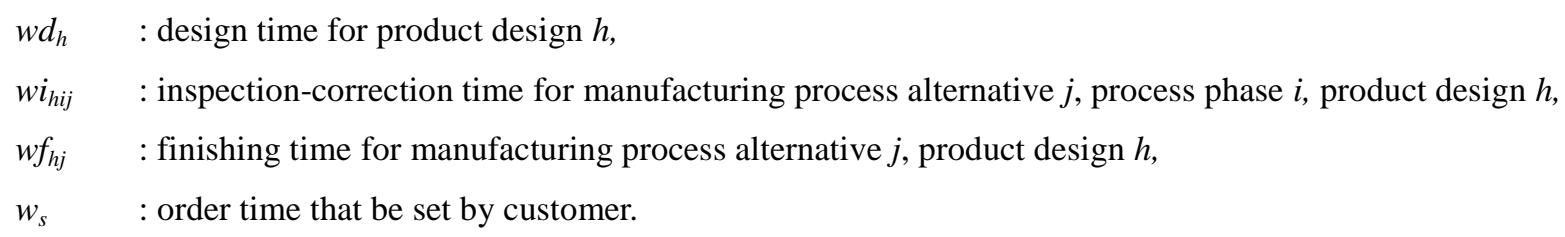

Decision Variables:

$x_{h} \quad$ : alternative of product design $h$,

$x_{p h} \quad:$ alternative of prevention process $p$ for product design $h$,

$x_{h i j} \quad$ : alternative of manufacturing process $j$ for a process phase $i$ for product design $h$,

$x_{f h j} \quad$ : alternative of finishing process $f$ for manufacturing process alternative $j$ for product design $h$.

The process alternatives include the selected supplier, outsourcing of work, materials, process, machines, and man power. Each alternative has a characteristic or cost requirement, tolerance, processing time, and number of units produced. All of the selected processes affect the final product, and thus the final product has the quality characteristic $y$ that resulted from a function of each process as shown in Eq. (1).

$y=f(R)$

where $R=\left[x_{h}, x_{p h}, x_{h i j}, x_{f h j}\right]$ is the process combination that consists of the product design process, prevention process, manufacturing process, and finishing process, respectively. All decision variables $\left(x_{h}, x_{p h}, x_{h i j}, x_{f h j}\right)$ are zero-one variables. A conceptual model is shown in Fig. 1.

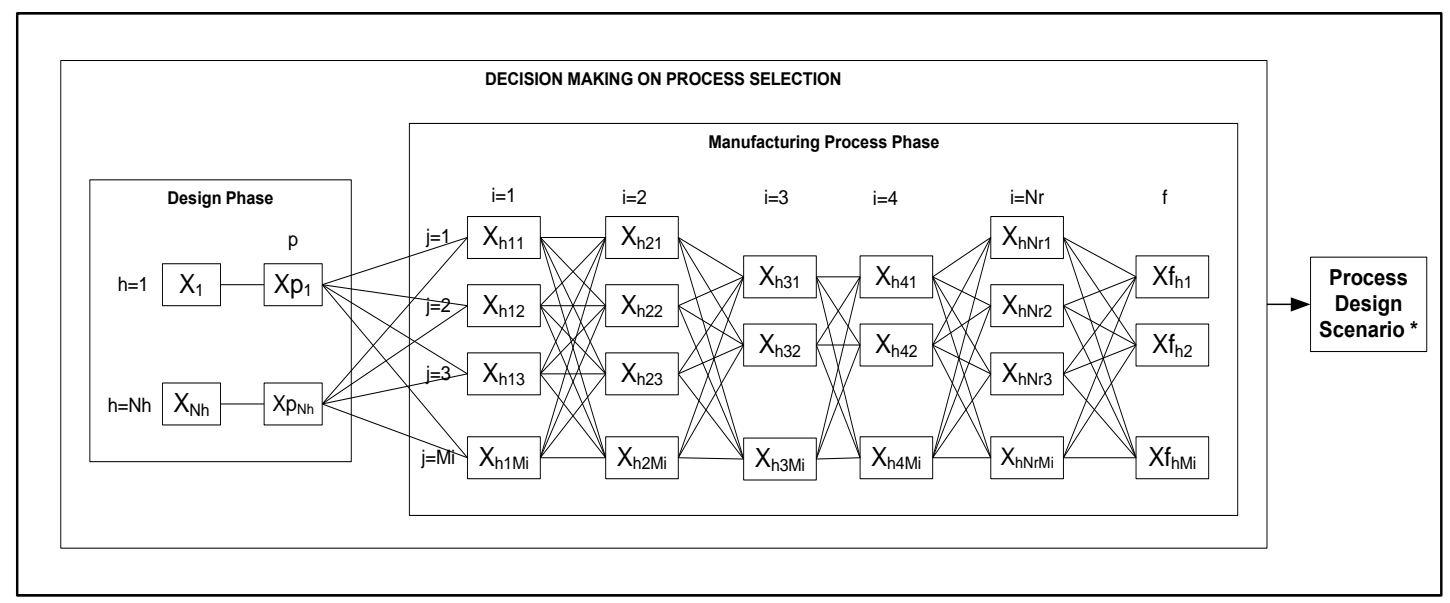

Fig. 1. Conceptual model of the process selection

The design cost, $D(R)$, refers to the cost that is used to produce alternative designs of the product. In this study, the design cost was calculated by multiplying the design cost for a specific design, $c d_{h}$, by the variable of the design alternatives that can be selected, $x_{h}$, which is a zero-one variable.

$D(R)=\sum_{h=1}^{N h} c d_{h} x_{h}$

The prevention cost, $P(R)$, is the cost to evaluate a design to ensure that the manufacturing process to meet the target. For this research, the prevention cost was formulated as shown in Eq. (3), where $c p_{h}$ is the prevention cost and $x_{p h}$ is the alternative variable of the prevention process.

$P(R)=\sum_{h=1}^{N h} c p_{h} x_{p h}$ 
The manufacturing cost, $M(R)$, is the cost to producing a product based on an estimation of the manufacturing cost on the shop floor. The manufacturing cost is calculated by multiplying the manufacturing cost for a selected process, $c m_{h i j}$, by the alternative variable of process $x_{h i j}$, as shown in Eq. (4).

$$
M(R)=\sum_{h=1}^{N h} \sum_{i=1}^{N r} \sum_{j=1}^{M i} c m_{h i j} x_{h i j}
$$

The expected quality loss, $Q(R)$, is a function of the process variance, $\sigma^{2}$. For this paper, we used the Taguchi quadratic loss function (Taguchi et al., 2005; Mustajib, 2012), as in Eq. (5).

$$
L(y)=A_{p}(y-\tau)^{2}
$$

where $L(y)$ is the loss function in monetary value of final product with quality characteristic $y, \tau$ is target quality for the characteristics required by the customer, and $A_{p}$ is the coefficient of the quality loss function. Calculation for the tolerance of the finished product is based on the tolerance function for each component involved. According to Irianto and Rachmat (2008), the expected quality loss function is formulated as in Eq. (6).

$$
Q(R)=A_{p}\left(\sum_{h=1}^{N h} \sum_{i=1}^{N r} \sum_{j=1}^{M i}\left(\left.\frac{\partial y}{\partial x}\right|_{\tau_{y h i}}\right)^{2}\left(\frac{t_{h i j}}{3}\right)^{2} x_{h i j}\right)
$$

The cost of inspection-correction is a function of the tolerance. The number of inspected units influences the magnitude of the inspection-correction costs. In this study, we considered the possibility that products that did not meet the tolerance limits could be re-processed or corrected. As such, each product had a chance to be corrected, leading to the inspection-correction cost formulation shown in Eq. (7).

$$
I K(R)=\sum_{h=1}^{N h} \sum_{i=1}^{N r} \sum_{j=1}^{M i} c i_{h i j}\left(n p_{h i j}\left(1+\frac{\overline{P_{h i j}}}{1-\overline{P_{h i j}}}\right)\right) x_{h i j}
$$

The finishing cost is the cost needed to ensure that the products meet the target specifications of the customer. The finishing cost, $F(R)$, is a function of the overall finishing cost, as shown in Eq. (8).

$$
F(R)=\sum_{h=1}^{N h} \sum_{j=1}^{M i} c f_{h j} x_{f h j}
$$

Hence, the optimization model for the process selection by minimizing the Total Cost, $T C(R)$, can be expressed formally as follows:

$$
\begin{aligned}
& \operatorname{Min} T C(R)=\sum_{h=1}^{N h} c d_{h} x_{h}+\sum_{h=1}^{N h} c p_{h} x_{p h}+\sum_{h=1}^{N h} \sum_{i=1}^{N r} \sum_{j=1}^{M i} c m_{h i j} x_{h i j}+A_{p}\left(\sum_{h=1}^{N h} \sum_{i=1}^{N r} \sum_{j=1}^{M i}\left(\left.\frac{\partial y}{\partial x}\right|_{\tau_{h i}}\right)^{2}\left(\frac{t_{h i j}}{3}\right)^{2} x_{h i j}\right)+\sum_{h=1}^{N h} \sum_{i=1}^{N r} \sum_{j=1}^{M i} c i_{h i j}\left(n p_{h i j}\left(1+\frac{\bar{P}_{h i j}}{1-\bar{P}_{h i j}}\right)\right) x_{h i j} \\
& +\sum_{h=1}^{N h} \sum_{j=1}^{M i} c f_{h j} x_{f h j}
\end{aligned}
$$

Equation (9) indicates that the proposed model integrates offline and online quality control, considers design and manufacturing tolerance, and balances between cost, tolerance, and delivery time. This optimization problem also has three constraints; 1) the tolerable quality limit or specification, 2) manufacturing time, and 3) zero-one index. To meet the quality specifications, the quality tolerance of final product, $t_{p}$, must be less than or equal to the specified or targeted quality tolerance, $t_{k}\left(t_{p} \leq t_{k}\right.$ or $\left.t_{p}^{2} \leq t_{k}^{2}\right)$, as expressed in Eq. (10). 
$\sum_{h=1}^{N h} \sum_{i=1}^{N r} \sum_{j=1}^{M i}\left(\left.\frac{\partial y}{\partial x}\right|_{\tau_{y h i}}\right)^{2}\left(t_{h i j}\right)^{2} x_{h i j} \leq\left(t_{k}\right)^{2}$

The total time required to produce the final product is a combination of the design time and manufacturing time. The design time, $w d$, in this model is the time needed to draft the design and test. The manufacturing time is the time required to produce the product. This time consists of the processing time to make the finished product, inspection time, correction time, and finishing time. This time limit can be expressed mathematically as:

$\sum_{h=1}^{N h} n d_{h} w d_{h} x_{h}+\sum_{h=1}^{N h} \sum_{i=1}^{N r} \sum_{j=1}^{M i} n i_{h i j} w i_{h i j} x_{h i j}+\sum_{h=1}^{N h} \sum_{j=1}^{M i} n f_{h j} w f_{h j} x_{f h j} \leq w_{s}$

Finally, this model is also defined such that all of the constraints must be positive (i.e., as in Eq. (12) to (15)).

$\sum_{h=1}^{N h} x_{h}=1, \quad x_{h} \in\{0,1\}$

$\sum_{h=1}^{N h} x_{p h}=1, \quad x_{p h} \in\{0,1\}$

$\sum_{j=1}^{M i} x_{h i j}=1, \quad x_{h i j} \in\{0,1\} \quad \forall_{h, i}$,

$\sum_{j=1}^{M i} x_{f h j}=1, \quad x_{f h j} \in\{0,1\} \quad \forall_{f, h}$,

\section{Numerical Example}

\subsection{The Case Description}

We considered small-medium sized make-to-order companies that can share their facilities to produce crimpers as a case study. A crimper is an assembly part in food-packaging machines (see Fig. 2). The quality characteristics of a crimper are the pressure, force, and power dimensions of the crimper profile, which are highly affected by the heat treatment and type of materials used. The critical dimension parameters that affect the quality of a crimper include the cylinder length $(L)$, the hole diameter $(d)$, the profile width $(w)$, the profile length $(l)$, and the profile height $(h)$. The targets of these dimensions are $\tau_{L}, \tau_{d}, \tau_{w}, \tau_{b} \tau_{h}$, respectively. From the design measurements, the quality characteristics of the final crimper product were $L(87 \pm 0.3) \mathrm{mm} ; d(45 \pm 0.3) \mathrm{mm} ; w(5.5 \pm 0.2) \mathrm{mm} ; l(8.3 \pm 0.3) \mathrm{mm} ; h(7.95 \pm 0.3)$ $\mathrm{mm}$.

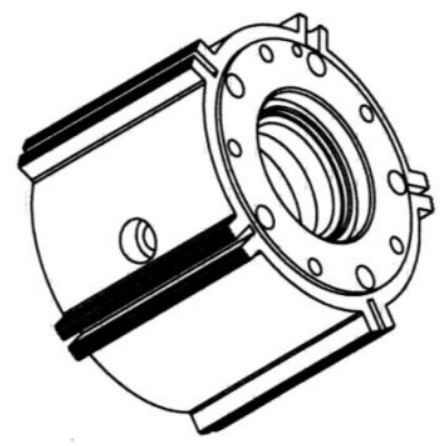

Fig. 2. Crimper (Mustajib and Irianto, 2010).

A quality characteristic of final product design $(y)$ is a function of the quality characteristics of the various dimensions. According to Irianto and Rachmat (2008), the quality characteristic of finished crimper is the bending 
stress, which can be expressed as

$$
y=f(L, d, w, l, h)=4.71 \frac{d^{3} \cdot h}{L \cdot l \cdot w^{2}}
$$

We discovered that the allowed tolerance for the finished product was $0.84 \mathrm{~kg} / \mathrm{mm}^{2}$, and the delivery time constraint was 10.5 days per crimper. Using Indonesian Rupiah (IDR) as the unit of account for valuing goods, the company decided that $\mathrm{Cr}$, the average cost per unit from the manufacturer to the customers of not complying with the target value (as a product guarantee), should be IDR 3,528,000. Hence, the $A_{p}$ value was calculated to be $A_{p}=C r / t_{k}^{2}=$ $3,528,000 /(0.84)^{2}=5,000,000$.

In this study, we considered the product design and manufacturing process phases (see Fig. 1). In the product design phase, the company had two different crimper designs $\left(x_{h} ; h=1,2\right)$. Each unique product design needed a different product design test. Hence, two product design tests $\left(x_{p h} ; p h=1,2\right)$ were considered in this study. The following manufacturing process phase consisted of a process to generate the proper cylinder length, hole diameter, profile width, profile length, and profile height. In the cylinder length creation process $(i=1)$, the company had three different material suppliers $(j)$, as noted here $x_{h i j:} h=1,2 ; i=1 ; j=1,2,3$. In the hole creation $(i=2)$ process, the company had three turning machines $(j)$ to make the hole for each design $(h)$ as noted here $x_{h i j:} h=1,2 ; i=2 ; j=1,2,3$. For the profile width $(i=3)$ and length $(i=4)$ processes, the company had two milling machines that had different processing speeds. The notations for the profile width and length processes are $x_{h i j}: h=1,2 ; i=3 ; j=1,2$ and $x_{h i j:} h=$ 1,$2 ; i=4 ; j=1,2$, respectively. For the profile height process $(i=5)$, the company had three outsourcing options $(j)$ noted here as $x_{h i j}: h=1,2 ; i=5 ; j=1,2,3$. Finally, for the finishing process, the company had two hardening machines (j) noted here as $x_{f h j:} h=1,2 ; j=1,2$. Thus, we had a total of 864 distinct scenarios for the product design and manufacturing process selection.

\subsection{Result and Discussion}

In this sub-section, we present the results of the analysis and discuss the main contribution of this paper, which is a comprehensive model for selecting the proper manufacturing scenario by accounting for the offline quality control at the product design phase, and the online quality control at the manufacturing process phase. We also briefly discuss the optimal scenario obtained from the model, which was a compromise between three key factors: the quality, delivery time, and total cost.

We applied Lingo 11 to determine the optimization process. The globally optimal solution with the least total cost (IDR 7,949,135) was obtained after 121 iterations and the elapsed runtime was 1 second on a personal computer with Intel(R) Core(TM) i5-440 CPU @3.10GHz. However, it should also be noted that based on the computational complexity theory, the decision version of an integer linear programming problem similar to the one proposed in this study is NP-complete (see, for example, Garey and Johnson, 1979; Lenstra, 1983), heuristic methods might need to be used for searching the optimal solution when we try to analyze large-scale problems with much more processes and alternatives. The optimal process scenario was scenario number 750: $x_{2}-x_{p 2}-x_{212}-x_{222}-x_{231}-x_{241}-x_{253}-x_{f 22}$. This scenario number corresponds to the second design and design test, getting the materials from the second supplier, and using the second turning machine to make the hole, the first milling machine to make the profile width and length, sending the material to third outsourcing company to make the profile height, and finally using the second hardening machine in the finishing process. This processing scenario achieved the lowest total cost with a tolerance of $0.563425 \mathrm{~kg} / \mathrm{mm}$ and a delivery time of 9.05 days.

A second-order contour plot that shows the contour levels of the costs with respect to different times and tolerances is shown in Fig. 3. This figure shows that a tighter tolerance would increase the total cost by as much as $5.8 \%$. The higher total cost resulted from increasing the design, prevention, manufacturing, inspection-correction, and finishing costs by $9.77 \%, 12.6 \%, 5.24 \%, 5.26 \%$, and $15.16 \%$ on average compared to the optimal solution, respectively. On the other hand, a tighter tolerance reduces the quality loss from the optimal solution by $3.09 \%$ on average (see Table 1 ). 


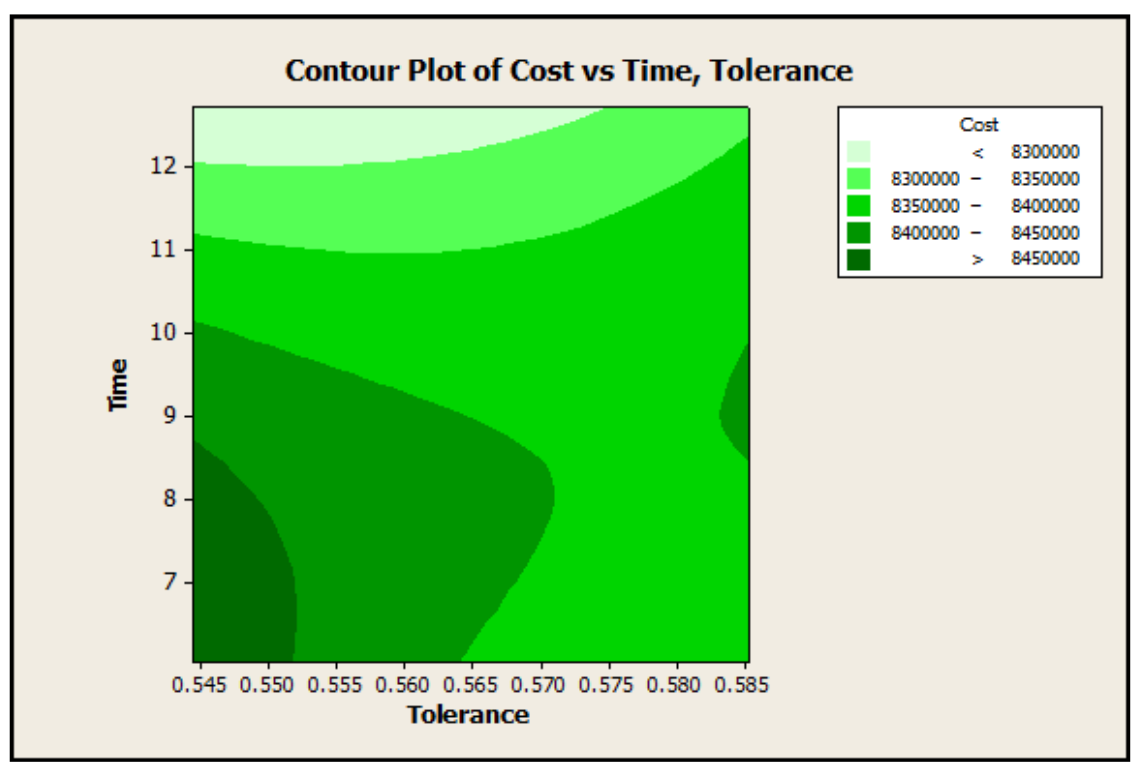

Fig. 3. The second-order contour plot of the costs with respect to different time and tolerance

A lenient tolerance would increase the total costs and quality losses by $5.61 \%$ and $4.21 \%$ on average, respectively. Although a more lenient tolerance usually corresponds to selecting processes (i.e., scenarios) with lower manufacturing and inspection-correction costs, we also found that a lenient tolerance would increase the design, prevention, manufacturing, inspection-correction, and finishing costs by as much as $9.67 \%, 12.54 \%, 4.86 \%, 4.88 \%$, and $15.08 \%$, respectively. Hence, it can be inferred that the tolerance should not be set to the highest level because it would increase some of the costs. However, the tolerance should not be made too lenient because it would increase the total cost through some of the other costs.

In terms of the delivery time, imposing a tighter delivery time boosted the cost by as much as $6.29 \%$ on average as compared to the optimal solution. The costs with a tighter delivery time were greater than the optimal solution, particularly the design, prevention, manufacturing, inspection-correction, and finishing costs by $9.73 \%, 12.68 \%, 5.62 \%$, $5.64 \%$ and $20.35 \%$, respectively, on average as described in Table 1 . The cost of the quality loss experience decreased by $2.28 \%$ on average. Similar to a tighter delivery time, a looser delivery time will also increase design costs, prevention cost, and finishing cost as compared to the optimal solution as much as 5.34\%. Thus, this model serves gives a proper balance between the tolerance level and delivery time. This model can determine the optimal tolerance level and delivery time to yield the lowest total cost.

Table 1 . The effect of the tolerance and the delivery time to the costs.

\begin{tabular}{cccccccc}
\hline Item & $T C(R)$ & $D(R)$ & $P(R)$ & $M(R)$ & $Q(R)$ & $D(R)$ & $I K(R)$ \\
\hline Optimal Solution & $7,949,135$ & 199,412 & 400,000 & $3,485,113$ & 177,167 & $3,489,873$ & 197,570 \\
\hline \multicolumn{1}{c}{ Item } & $T C(R)$ & $D(R)$ & $P(R)$ & $M(R)$ & $Q(R)$ & $D(R)$ & $I K(R)$ \\
\hline Tighter tolerance & $8,409,853$ & 218,904 & 450,392 & $3,667,620$ & 171,702 & $3,673,313$ & 227,517 \\
Lenient tolerance & $8,395,412$ & 218,698 & 450,147 & $3,654,324$ & 184,631 & $3,660,241$ & 227,370 \\
Tighter delivery time & $8,448,763$ & 218,805 & 450,720 & $3,680,891$ & 173,132 & $3,686,716$ & 237,772 \\
Looser delivery time & $8,373,294$ & 218,833 & 450,000 & $3,649,488$ & 179,465 & $3,655,242$ & 220,357 \\
\hline
\end{tabular}

This result confirms that it is a comprehensive model that incorporates both the offline and online quality control. It balances the quality, cost and delivery time. The result also provides evidence that the model can be applied to more than one product design. In this study, we applied the model to two product designs and found that the optimal one was the second design.

Regarding the quality, cost, and delivery time, our model led to the lowest total cost and inherently balances the quality level and delivery time as well. For the case study, the model proves its effectiveness by giving the optimal solution with the lowest total cost with an insignificant change from the best quality (the optimal tolerance was only $3.38 \%$ more lenient than the tightest tolerance). However, this led to a significant difference from the fastest delivery 
time (approximately $33.19 \%$ slower than the fastest production process scenario).

Using this result we can make a decision regarding the manufacturing process selection based on the following conditions:

(a) If the MTO manufacturer considers the minimum cost to be the main factor for decision-making, the proposed model will offer the best solution because it can give the minimum total cost.

(b) In the case study presented in this paper, if the MTO manufacturer considered the product quality to be the main decision making factor, the proposed model could still provide the best choice because the difference between the tolerance for the optimal solution and the tightest tolerance scenario was insignificant.

\subsection{Sensitivity Analysis}

The increase in various parameters with the objective values is shown in Table 2. As seen in the Table 2, the higher the changes in each parameter, the higher total cost. The highest total cost changes corresponded with changes in the manufacturing and inspection-correction cost. The total cost will drop or rise approximately $4.39 \%$ for every $10 \%$ reduction or increase to the parameters. This shows that if the company wanted to significantly decrease the total cost, this could be done by reducing the manufacturing cost or inspection-correction cost. Interestingly, the model provided the same optimal process scenario (scenario number 750) for a variety of changes to the input parameter; changes to the time constraint of $20 \%$ and $50 \%$ changes were the exception. This implies that the proposed model is a robust model.

Table 2. Sensitivity Analysis

\begin{tabular}{|c|c|c|c|c|c|c|c|c|}
\hline \multirow{2}{*}{\multicolumn{2}{|c|}{ Parameter }} & \multicolumn{7}{|c|}{ Percentage of Changes } \\
\hline & & \multirow{2}{*}{$\frac{-100 \%}{7,749,726}$} & \multirow{2}{*}{$\frac{-50 \%}{7,8494,32}$} & \multirow{2}{*}{$\begin{array}{c}-20 \% \\
7,909,256\end{array}$} & \multirow{2}{*}{$\begin{array}{c}0 \\
7,949,138\end{array}$} & \multirow{2}{*}{\begin{tabular}{c|}
$20 \%$ \\
$7,989,020$
\end{tabular}} & \multirow{2}{*}{$\begin{array}{c}50 \% \\
8,048,844\end{array}$} & \multirow{2}{*}{$\begin{array}{c}100 \% \\
8,148,550\end{array}$} \\
\hline & $\mathrm{TC}$ & & & & & & & \\
\hline & $\mathrm{SN}$ & 750 & 750 & 750 & 750 & 750 & 750 & 750 \\
\hline \multirow{2}{*}{$P(R)$} & $\mathrm{TC}$ & $7,549,138$ & $7,749,138$ & $7,869,138$ & $7,949,138$ & $8,029,138$ & $8,149,138$ & $8,349,138$ \\
\hline & SN & 750 & 750 & 750 & 750 & 750 & 750 & 750 \\
\hline \multirow{2}{*}{$M(R)$} & $\mathrm{TC}$ & $4,464,025$ & $6,206,582$ & $7,252,116$ & $7,949,138$ & $8,646,160$ & $9,691,695$ & $11,434,250$ \\
\hline & SN & 750 & 750 & 750 & 750 & 750 & 750 & 750 \\
\hline \multirow{2}{*}{$I K(R)$} & $\mathrm{TC}$ & $4,459,265$ & $6,204,200$ & $7,251,163$ & $7,949,138$ & $8,647,113$ & $9,694,073$ & $11,439,010$ \\
\hline & SN & 750 & 750 & 750 & 750 & 750 & 750 & 750 \\
\hline \multirow{2}{*}{$F(R)$} & $\mathrm{TC}$ & $7,751,568$ & $7,850,353$ & $7,909,624$ & $7,949,138$ & $7,988,652$ & $8,047,923$ & $8,146,708$ \\
\hline & $\mathrm{SN}$ & 750 & 750 & 750 & 750 & 750 & 750 & 750 \\
\hline \multirow{2}{*}{$A p$} & $\mathrm{TC}$ & $7,771,968$ & $7,860,548$ & $7,913,698$ & $7,949,138$ & $7,984,568$ & $8,037,718$ & $8,126,308$ \\
\hline & SN & 750 & 750 & 750 & 750 & 750 & 750 & 750 \\
\hline \multirow{2}{*}{$Q R)$} & $\mathrm{TC}$ & $7,771,968$ & $7,860,548$ & 7,913,698 & $7,949,138$ & $7,984,568$ & $8,037,718$ & $8,126,308$ \\
\hline & $\mathrm{SN}$ & 750 & 750 & 750 & 750 & 750 & 750 & 750 \\
\hline \multirow{2}{*}{$\mathrm{CoQ}$} & $\mathrm{TC}$ & $7,949,138$ & $7,949,138$ & $7,949,138$ & $7,949,138$ & $7,949,138$ & $7,949,138$ & $7,949,138$ \\
\hline & $\mathrm{SN}$ & 750 & 750 & 750 & 750 & 750 & 750 & 750 \\
\hline \multirow{2}{*}{ CoT } & $\mathrm{TC}$ & $7,949,138$ & $7,949,138$ & $7,949,138$ & $7,949,138$ & $8,009,268$ & $8,153,229$ & infeasible \\
\hline & SN & 750 & 750 & 750 & 750 & 749 & 821 & infeasible \\
\hline
\end{tabular}

TC: Total Cost

CoQ: Constrain of Quality

SN: Scenario Number

CoT: Constrain of Time

\section{Comparing Proposed Model and Previous Studies}

Kumar et al. (2008) has successfully developed two optimization models to help management select process improvement opportunities. The first model maximized the sigma quality level of a process under a cost constraint, and the second model provided alternatives to maximize profit. The costs considered in their model were a consequence of the production process phase. Mustajib and Irianto (2010) recommended a model to select alternative processes and determine the unit of production for each stage to maximize profits based on the costs during the production process phase and online quality control. However, our selection process model is able to minimize the total cost by considering not only the costs related to the production process but also the product design phase, considering both 
online and offline quality control.

The model of Irianto and Rachmat (2008) made the best solution for the assigned production process considering appraisal cost. Compare to their model that is only suitable for single product designs and considers online quality control, we have created an advanced model considering the design aspect and conformance costs. Therefore, our model is able to select a design from multiple of product designs. This proposed model not only examines the aspects of the online quality control but also the offline quality control. Moreover, the proposed model can integrate both types of quality control. Regarding the tolerance synthesis, the proposed model takes both design tolerance and manufacturing tolerance into account as an advantage over those models in (Wang and Liang, 2005; Peng et al., 2008; Robles and Roy, 2004; Mustajib and Irianto, 2010), where only manufacturing tolerance was considered. Hence, using this new comprehensive model, we can select a product design and production process to minimize the total cost while maintaining a good quality level and reasonable delivery time.

\section{Conclusion}

The proposed model successfully simultaneously integrates quality, cost, and delivery time as well as offline and online quality control. Our model can balance the loss of quality so that can the needs of both of the manufacturer and customer are satisfied. This model is also robust; thus, it can be implemented in numerous situations. The optimal solution of this model is in the form of the process design scenarios of the selected processes. The developed model can be applied to small-scale MTO manufacturers because it can meet the required specifications according to the customer order. The result provides the cheapest total cost, and the quality is insignificantly different from the best quality, although the delivery time is significantly different than the fastest delivery time.

Our model considers prevention and appraisal costs to ensure that the product meets the customers' expectations. However, we did not consider costs related to non-conformance costs (e.g., internal and external failure costs) in this model. Future research may include non-conformance costs and the cost of quality improvement.

\section{Acknowledgements}

The first author would like to acknowledge the DIKTI Scholarship from Ministry of Research, Technology and Higher Education of Indonesia, which grants a beneficial opportunity and supports his study in the doctoral program at National Taiwan University of Science and Technology, Taiwan. This study is also based upon work supported in part by the ROC Ministry of Science and Technology under grant number MOST103-2410-H-011-012-MY3. Any opinions, findings, and conclusions or recommendations expressed herein are those of the authors and do not necessarily reflect the views of the sponsors.

\section{References}

Andolfatto, L., Thiébaut, F., Lartigue, C., and Douilly, M., Quality- and cost-driven assembly technique selection and geometrical tolerance allocation for mechanical structure assembly, Journal of Manufacturing Systems, Vol. 33, (2014), pp. 103-115, DOI:10.1016/j.jmsy.2013.03.003.

Aravindan, P., Devadasan, S. R., Dharmendra, B. V, and Selladurai, V., Continuous quality improvement through Taguchi's online quality control methods, International Journal of Operation \& Production Management, Vol. 15, No. 7, (1995)., pp. 60-77.

Boyer, K. K., and Lewis, M. W., Competitive priorities: investigating the need for trade-offs in operations strategy, Production and Operations Management, Vol. 11, No. 1, (2002), pp. 9-20, DOI:10.1111/j.1937-5956.2002.tb00181.x

Calosso, T., Cantamessa, M., Vu, D., and Villa, A., Production planning and order acceptance in business to business electronic commerce, International Journal of Production Economics, Vol. 85, (2003), pp. 233-249, DOI:10.1016/S0925-5273(03)00112-9.

Díaz-Garrido, E., Martín-Peña, M. L., and Sánchez-López, J. M., Competitive priorities in operations: development of an indicator of strategic position, CIRP Journal of Manufacturing Science and Technology, Vol. 4, (2011), pp. 118-125, DOI:10.1016/j.cirpj.2011.02.004.

Dwijayanti, K., and Aoyama, H., Basic study in process planning for turning-milling center based on machining feature recognition, Journal of Advanced Mechanical Design, Systems, and Manufacturing, Vol. 8, No. 4, (2014), pp. 1-14, DOI:10.1299/jamdsm.2014jamdsm00.

Ebadian, M., Rabbani, M., Jolai, F., Torabi, S. A., and Tavakkoli-Moghaddam, R., A new decision-making structure 
for the order entry stage in make-to-order environments, International Journal of Production Economics, Vol. 111, (2008), pp. 351-367, DOI:10.1016/j.ijpe.2007.01.004.

Feng, C. X., Wang, J., and Wang, J. S., An optimization model for concurrent selection of tolerances and suppliers, Computers and Industrial Engineering, Vol. 40, (2001), pp. 15-33, DOI:10.1016/S0360-8352(00)00047-4

Fine, C. H., Golany, B., and Naseraldin, H. Modeling tradeoffs in three-dimensional concurrent engineering: A goal programming approach, Journal of Operations Management, Vol. 23, (2005), pp. 389-403, DOI:10.1016/j.jom.2004.09.005.

Garey, M. R., and Johnson, D. S. Computers and intractability: a guide to the theory of NP-completeness. (Vi. Klee, Ed.) (1979), New York: W. H. Freeman and Company.

Gryna, M.F., Chua, R.C.H., and DeFeo, J. A., Juran's quality planning and analysis: for enterprise quality (5th ed.) (2005), New York: McGraw-Hill.

Haskose, A., Kingsman, B., and Worthington, D., Performance analysis of make-to-order manufacturing systems under different workload control regimes, International Journal of Production Economics, Vol. 90, (2004), pp. 169-186, DOI:10.1016/S0925-5273(03)00052-5.

Irianto, D., and Rachmat, D., A model for optimizing process selection for MTO manufacturer with appraisal cost, In APIEMS, (2008), pp. 220-225. Bali, Indonesia.

Kumar, U. D., Nowicki, D., Ramírez-Márquez, J. E., and Verma, D., On the optimal selection of process alternatives in a Six Sigma implementation, International Journal of Production Economics, Vol. 111, (2008), pp. 456-467, DOI:10.1016/j.ijpe.2007.02.002.

Lenstra, J. H. W. Integer Programming with a fixed number of variables. Mathematics of Operations Research, Vol. 8, No. 4, (1983). pp. 538-548. DOI:10.1287/moor.8.4.538.

Li, B., Yang, X., Hu, Y., and Zhang, D. Quality design of tolerance allocation for sheet metal assembly with resistance spot weld, International Journal of Production Research, Vol. 47, No. 6, (2009), pp. 1695-1711, DOI: $10.1080 / 00207540701644193$.

Lin, C.W., Simultaneous optimal design of parameters and tolerance of bearing locations for high-speed machine tools using a genetic algorithm and Monte Carlo simulation method, International Journal of Precision Engineering and Manufacturing, Vol. 13, No. 11, (2012), pp. 1983-1988, DOI:10.1007/s12541-012-0261-6.

Muda, S., and Hendry, L., Developing a new world class model for small and medium sized make-to-order companies, International Journal of Production Economics, Vol. 78, (2002), pp. 295-310, DOI:10.1016/S0925-5273(01)00085-8.

Mustajib, M. I., Concurrent engineering of tolerance synthesis and process selection for products with multiple quality characteristcs considering process capability, Makara Journal of Technology Series, Vol. 16, No. 1, (2012), pp. $7-14$.

Mustajib, M. I., and Irianto, D., An integrated model for process selection and quality improvement in multi-stage processes. Journal of Advanced Manufacturing Systems, Vol. 09, No. 1, (2010), pp. 31-48, DOI:10.1142/S0219686710001788.

Onwubolu, G. C., On and off-line quality control for product design and manufacturing processes. The South African Journal of Industrial Engineering, Vol. 8, No. 2, (1997). pp. 61-71. DOI:10.1017/CBO9781107415324.004.

Peng, H. P., Jiang, X. Q., and Liu, X. J., Concurrent optimal allocation of design and process tolerances for mechanical assemblies with interrelated dimension chains, International Journal of Production Research, Vol. 46 (March), (2008), pp. 6963-6979, DOI:10.1080/00207540701427037.

Robles, N., and Roy, U., Optimal tolerance allocation and process-sequence selection incorporating manufacturing capacities and quality issues. Journal of Manufacturing Systems, Vol. 23, No. 2, (2004), pp. 127-133, DOI: $10.1016 / \mathrm{S} 0278-6125(05) 00002-6$.

Shimizu, Y Y., Waki, T., and Yoo, J.-K., Multi-objective optimization on a sequencing planning of mixed-model assembly line, Journal of Advanced Mechanical Design, Systems, and Manufacturing, Vol. 5, No. 4, (2011), pp. 274-283, DOI:10.1299/jamdsm.5.274.

Singh, P. K., Jain, P. K., and Jain, S. C., Important issues in tolerance design of mechanical assemblies. Part 2: Tolerance synthesis, Proceedings of the Institution of Mechanical Engineers, Part B: Journal of Engineering Manufacture, Vol. 223, (2009), pp. 1249-1287, DOI:10.1243/09544054jem1304b.

Taguchi, G., Chowdhury, S., and Wu, Y., Taguchi's quality engineering handbook (2005), New Jersey: John Willey and Sons Hoboken.

Tehrani, H., Sugimura, N., Tanimizu, Y., and Iwamura, K., A search algorithm for generating alternative process plans in flexible manufacturing system, Journal of Advanced Mechanical Design, Systems, and Manufacturing, Vol. 1, No. 5, (2007), pp. 706-716, DOI:10.1299/jamdsm.1.706.

Wang, P., and Liang, M., An integrated approach to tolerance synthesis, process selection and machining parameter optimization problems, International Journal of Production Research, Vol. 43 (March), (2005), pp. 2237-2262, DOI: $10.1080 / 00207540500050063$. 
Jerusalem, Lin and Irianto, Journal of Advanced Mechanical Design, Systems, and Manufacturing, Vol.10, No.4 (2016)

Zhang, H.C., Advanced tolerancing techniques (1997), New York: John Willey \& Sons. 